\title{
The association between executive functioning, coping styles and depressive symptoms in patients with Multiple Sclerosis
}

Citation for published version (APA):

Van Heugten, C., Köhler, S., Francke, M., \& Bol, Y. (2019). The association between executive functioning, coping styles and depressive symptoms in patients with Multiple Sclerosis. Multiple Sclerosis and Related Disorders, 36, [101392]. https://doi.org/10.1016/j.msard.2019.101392

Document status and date:

Published: 01/11/2019

DOI:

10.1016/j.msard.2019.101392

Document Version:

Publisher's PDF, also known as Version of record

\section{Document license:}

Taverne

Please check the document version of this publication:

- A submitted manuscript is the version of the article upon submission and before peer-review. There can be important differences between the submitted version and the official published version of record.

People interested in the research are advised to contact the author for the final version of the publication, or visit the DOI to the publisher's website.

- The final author version and the galley proof are versions of the publication after peer review.

- The final published version features the final layout of the paper including the volume, issue and page numbers.

Link to publication

\footnotetext{
General rights rights.

- You may freely distribute the URL identifying the publication in the public portal. please follow below link for the End User Agreement:

www.umlib.nl/taverne-license

Take down policy

If you believe that this document breaches copyright please contact us at:

repository@maastrichtuniversity.nl

providing details and we will investigate your claim.
}

Copyright and moral rights for the publications made accessible in the public portal are retained by the authors and/or other copyright owners and it is a condition of accessing publications that users recognise and abide by the legal requirements associated with these

- Users may download and print one copy of any publication from the public portal for the purpose of private study or research.

- You may not further distribute the material or use it for any profit-making activity or commercial gain

If the publication is distributed under the terms of Article $25 \mathrm{fa}$ of the Dutch Copyright Act, indicated by the "Taverne" license above, 


\title{
The association between executive functioning, coping styles and depressive symptoms in patients with Multiple Sclerosis
}

\author{
C. Van Heugten ${ }^{\mathrm{a}, \mathrm{b}, \mathrm{c}}$, S. Köhler ${ }^{\mathrm{a}}$, M. Francke ${ }^{\mathrm{d}}$, Y. Bol ${ }^{\mathrm{d}, *}$ \\ ${ }^{a}$ Maastricht University Medical Center, School for Mental Health and Neuroscience, Maastricht, the Netherlands \\ ${ }^{\mathrm{b}}$ Maastricht University, Department of Neuropsychology \& Psychopharmacology, Maastricht, the Netherlands \\ ${ }^{c}$ Limburg Brain Injury Center, Maastricht University, Maastricht, the Netherlands \\ ${ }^{\mathrm{d}}$ Zuyderland Medical Centre, Department of Clinical and Medical Psychology, Sittard-Geleen, Heerlen, the Netherlands
}

\section{A R T I C L E I N F O}

\section{Keywords:}

Multiple Sclerosis

Coping styles

Depression

Executive functioning

\begin{abstract}
A B S T R A C T
Objectives: To investigate the direct, mediated and moderated relationships between executive functioning, coping and depressive symptoms in patients with multiple sclerosis (MS).

Methods: Cross-sectional cohort study of routine follow-up visits, including a standardized (neuro)psychological evaluation of 68 MS patients. Coping was measured with the Coping Inventory for Stressful Situations; Depressive symptoms with the subscale depression of the Hospital Anxiety and Depression Scale. Cognitive tests were reduced to a single 'executive function' factor by means of confirmatory factor analysis. Path analyses tested mediating and moderating effects of coping on the relation between executive functioning and depressive symptoms.

Results: Consistently, the executive functioning factor was not related to task-oriented and emotion-oriented coping. Better executive functioning, however, and less reliance on avoidance coping, was related to more depressive symptoms. Testing of the mediating path showed that executive dysfunctioning was indeed significantly related to more depressive symptoms by less reliance on avoidance coping. There was no additional direct effect of executive functioning on depressive symptoms and also no moderating effect of any coping style on the association between cognition and depressive symptoms.

Conclusion: Our findings suggest that task-oriented and emotion-oriented coping do not influence the relationship between executive functioning and depression in MS patients, but their mental health might benefit from more reliance on avoidance coping.
\end{abstract}

\section{Introduction}

Multiple sclerosis (MS) is a chronic neurological disease with a broad spectrum of symptoms. The consequences can include both physical and neuropsychiatric symptoms, which vary in nature and severity (Compston and Coles, 2008). Among the most prominent and disabling symptoms are cognitive impairment, depression, and fatigue (Chiaravalloti and DeLuca, 2008).

Coping strategies play a significant role in the ongoing adjustment process and are strongly associated with the overall quality of life (QoL) in chronic illness (Kristofferzon et al., 2011), including MS (Dennison et al., 2009). Coping has been defined as "a person's cognitive and behavioral efforts to manage the internal and external demands of the person-environment transaction that is appraised as taxing or exceeding the person's resources" (Folkman et al., 1986, p. 572). Many different theoretical models, definitions, classifications and conceptualizations of coping are found in the literature, leading to the use of different instruments to measure coping which makes comparison of studies difficult (Gregório et al., 2014). Coping styles may, for instance, be problem-focussed using problem solving strategies to actually reduce the problem, which is often denoted as adaptive coping; while emotion-focussed coping, which is more directed at reducing the emotional distress instead of the problem, is often denoted as maladaptive coping.

In a review it was shown that in MS, emotion-focussed coping styles have been associated with poor adjustment and lower QoL, while successful adjustment is most frequently seen in MS patients who use problem-focussed styles and who seek more social support (Dennison et al., 2009). Goretti et al. (2009) found that MS patients were less likely to use problem-focussed strategies but used avoiding strategies more frequently. The problem-focussed strategies were regarded as positive and influenced both mental and overall QoL positively.

\footnotetext{
* Corresponding author.

E-mail address: y.bol@zuyderland.nl (Y. Bol).
} 
The association between coping and psychological adjustment can be complicated in MS patients who are cognitively impaired. Cognitive impairment is often seen in MS, most commonly affecting mental speed, verbal and visual learning and memory, but attention, executive functioning and long-term memory may also be affected (Chiaravalloti and DeLuca, 2008). Goretti et al. (2010) found that a low performance on tasks measuring aspects of sustained attention and executive functioning was related to the use of more problem-focused strategies. Krpan et al. (2007) found that better executive functioning was positively related to the use of problem-focused strategies in patients with brain injury, but in our studies we did not find such a relationship (Wolters et al., 2011; Wolters Gregório et al., 2015).

It can be conceived that executive functions such as problem solving, self-monitoring, planning, and mental flexibility are needed to use coping strategies that require problem-solving skills (i.e. problem-focused strategies) which in turn will influence outcomes such as emotional functioning and QoL. Only a few studies investigated this relationship in MS. Arnett et al. (2002) found that the relationship between cognitive dysfunction and depression was moderated by coping. Specifically, in patients using either high levels of avoidance coping or low levels of problem-focused coping, cognitive dysfunction was most likely to be associated with depression. In a longitudinal study, the same group of researchers showed that coping not only moderates, but also partially mediates the relationship between cognitive dysfunction and depression (Rabinowitz and Arnett, 2009). Adaptive coping (i.e. problem-focused) was found to protect individuals from depressive symptoms related to cognitive deficits. However, maladaptive coping increased the risk of depression when cognitive deficits were present (i.e. moderation). In addition, cognitive deficits may impair an individual's ability to use adaptive coping strategies and thus increase the use of maladaptive strategies, which then leads to depression (i.e. mediation). There seems to be a direct as well as an indirect relaltion between cognitive functioning and depression via coping. Since both studies were done by the same group of researchers, the generalizability of these results shoud be established.

To further investigate the need for executive functions in adaptive coping with MS, the present study investigated the direct relationship between executive functioning and depression as well as the mediating and moderating effects of coping on the relationship between executive dysfunctions and depression. In exploring these relations, a priori hypotheses were not formulated.

\section{Methods}

\subsection{Participants and procedure}

Patient records of MS patients with a clinically definite MS (McDonald et al., 2001) were retrieved from the department of clinical and medical psychology and the outpatient clinic of the Academic MS Center of Zuyderland Medical Centre (location Sittard-Geleen), the Netherlands. The study was a cross-sectional cohort study using medical records of routine follow-up visits, including a standardized neuropsychological evaluation during a period from March 2009 to October 2014. For each patient, data of the first evaluation were used; the evaluation was equal for all patients (see measures). Exclusion criteria were the presence of other comorbid neurological impairments, insufficient Dutch language proficiency, and age below eighteen or above sixty-five. Basic demographic information was collected, including age, sex, marital status, working conditions and highest level of completed education. Education was categorized according to the Dutch education system (Verhage, 1964), with low education = senior secondary vocational education or lower and high education = university of applied sciences or higher.

Clinical characteristics of all patients (type of MS, disease duration, neurological disability) were collected from the hospital database. The Expanded Disability Status Scale (EDSS) provided a measure of neurological disability and was administered by an experienced neurologist (Kurtzke, 1983).

Measurements were part of a routine clinical assessment. All patients were informed by letter that their files could be used anonymously for research purposes, unless they objected. At the time of data collection, such procedure was sufficient and additional ethics approval was not necessary. The study was completed in accordance with the Helsinki Declaration.

\subsection{Measures}

\subsubsection{Coping}

Coping strategies were assessed using the Dutch version of the Coping Inventory for Stressful Situations (CISS) (De Ridder and Van Heck, 2004). This questionnaire consists of 48 items that focus on three separate coping strategies: task-oriented coping, emotion-oriented coping, and avoidance coping subscales. Items are assessed on a 5-point Likert scale, ranging from 1 (not at all) to 5 (very much). Higher scores on a subscale indicate a greater use of that particular coping strategy. The Dutch version of the CISS showed, in a similar fashion to the original version, a three-factor structure and good internal reliability (De Ridder and Van Heck, 2004). The Dutch CISS is also a reliable instrument in patients with neurological conditions, including MS (Brands et al., 2014, 2018).

\subsubsection{Depressive symptoms}

Depressive symptoms were assessed with the subscale depression of the Hospital Anxiety and Depression Scale (HADS) (Zigmond and Snaith, 1983). The depression subscale consists of 7 items, each rated on a 4-point verbal rating scale, with higher scores indicating higher levels of depression. Total scores range from 0 to 21. A score of 8 or higher is indicative for clinical significant symptoms of depression and the subscale is a valid screening tool for assessing major depression in MS patients (Honarmand and Feinstein, 2009).

\subsubsection{Fatigue}

The Fatigue Severity Scale (FSS) was used as a measure of the severity and impact of physical fatigue (Krupp et al., 1989). The FSS consists of 9 items, each assessed on a 7-point Likert scale, ranging from 1 (strongly disagree) to 7 (strongly agree). Scores across the items are averaged to produce an overall score that can range between 1 and 7. A score of 4 or higher indicates severe fatigue. The FSS has been found to be a reliable and valid measure of fatigue in MS patients (Amtmann et al., 2012; Rietberg et al., 2010).

The Checklist Individual Strength (CIS-20-R) was used as a second measure of fatigue (Vercoulen et al., 1999). The CIS-20-R consists of 20 statements, but this study only used 8 items that are related to the subjective experience of fatigue over the past two weeks. The items are rated on a 7-point Likert scale ranging from 1 (Yes, that is true) to 7 (No, that is not true). A score of 35 or higher on the subscale subjective fatigue is indicative of severe fatigue (Koopman et al., 2014). The subscale subjective fatigue of the CIS-20-R is a valid measure of MSrelated fatigue (Rietberg et al., 2010).

\subsubsection{Cognitive assessement}

To measure executive functioning seven neuropsychological tests were used. The Concept Shifting Test subtask C (CST-C) was used to measure divided attention and shifting (Van der Elst et al., 2006a). Divided attention and shifting are commonly impaired in MS (Chiaravalloti and DeLuca, 2008). We used the CST-C, because this test allows controlling for psychomotor speed, that is often impaired in MS.

The number of perseverative errors on the Wisconsin Card Sorting Test (WCST) was used as a measure of cognitive flexibility (Heaton et al., 2003). The WCST has good validity in the MS population and it has been found that patients with progressive MS, as compared to a population with a different chronic illness, make significantly more 
perseverative errors (Parmenter et al., 2007).

The oral version of the Letter Digit Substitution Test (LDST) was used as a measure of information processing speed (Van der Elst et al., 2006b). Reduced information processing speed is the most common cognitive impairment in MS and processing speed can predict performance on everyday tasks involving executive functioning (Chiaravalloti and DeLuca, 2008). We used the oral version to avoid motoric problems.

The Paced Auditory Serial Addition Test (PASAT) was used as a measure of working memory and information processing speed (Amato et al., 2006). The PASAT is a sensitive measure of cognitive impairment in MS (Chiaravalloti and DeLuca, 2008). We used the 3-second interval version, because it has been suggested that this version may be used in a wider range of MS-related impairment (Fischer et al., 1999).

Since verbal fluency tests have been found to be among the most sensitive measures of executive functioning in MS (Arnett et al., 2008; Henry and Beatty, 2006), we used two verbal fluency tasks: the semantic fluency task of the Groninger Intelligence Test (GIT) (Luteijn and Van der Ploeg, 1983) and the Controlled Oral Word Association Test (COWAT), a measure of phonological fluency (Schmand et al., 2008).

The Dutch version of the California Verbal Learning Test-II (CVLTII) was used to assess verbal learning and memory (Mulder et al., 1996). The CVLT-II is a valid and reliable measure of verbal learning and memory in MS (Benedict, 2005; Stegen et al., 2010). We used the difference between the long delay cued recall and the long delay free recall as a measure of executive functioning, since MS patients often have difficulties retrieving words from long-term memory storage (Chiaravalloti and DeLuca, 2008). Although the CVLT-II is primarily a memory test, executive functioning accounted for substantial variance (24-31\%) in CVLT-II performance for both Short- and Long-Delay Recall indexes in a mixed neurological sample, including MS patients (Hill et al., 2012).

The PASAT, the COWAT and the CVLT-II have all been proven to be highly sensitive and reliable measures in MS and are part of the core battery termed as the minimal assessment of cognitive function in MS (MACFIMS) (Benedict et al., 2005).

\subsection{Statistical analyses}

All variables were inspected for normality. Logarithmic transformations were applied to cognition variables in case variables were not normally distributed. For HADS depression scores, a square-root function was used. Impaired cognition was defined as a test score 1.5 standard deviations below the mean of the norm scores for each test based on the manual, which is equivalent to a $z$-score $<-1.5, t$ score $<35$ or a score in the 6 th to 7 th percentile.

The cognitive tests were reduced to a single 'executive function' (EF) factor by regressing the observed test scores on a continuous latent variable (i.e. confirmatory factor analysis). We used a mean and variance corrected maximum likelihood estimator to account for nonnormality in test scores. For reasons of efficiency and power, the EF factor was estimated in the larger sample of 122 patients for whom cognitive test data was available (Fig. 1). Since the CISS was added later to the routine clinical follow up, all other analyses were done with the complete dataset including the CISS data $(b=68)$.

Regression-based EF factor scores were calculated and used as an exogenous variable in further path analysis. Two path models were specified. In the first model (Fig. 2a), EF mediated the association between coping and depressive symptoms, and total, direct and indirect effects of coping styles were tested. In the second model (Fig. 2b), EF moderated the association between coping and depressive symptoms by testing the interaction between $\mathrm{EF}$ and coping styles on the depression outcome. Both models were adjusted for age, gender and education (low, high). Unstandardized path coefficients b are shown. One participant had missing information for education. We considered this to be missing at random and used full-information maximum likelihood (Stata command 'sem' with option 'mlmv') to include this participant in the analyses. All tests were two-sided with an alpha $<0.05$ considered significant. All analyses were done in Stata 13.1.

\section{Results}

\subsection{Demographic and clinical characteristics}

Demographic and clinical characteristics of the sample are shown in Tables 1 and 2. As can be seen, the sample used in path analysis was generally comparable to the full sample (Table 1). Most patients were female, had low education and a relapsing-remitting course. Fatigue was very prevalent and about $34 \%$ had clinically significant symptoms of depression according to the cut-off of the HADS-D. Impaired performance on individual tests measuring EF ranged between 3\% (CVLT delayed memory recall) to $33 \%$ (LDST).

\subsection{Correlational analyses}

Correlations between individual tests and coping and depression outcomes are shown in Table 3. The only significant correlations were

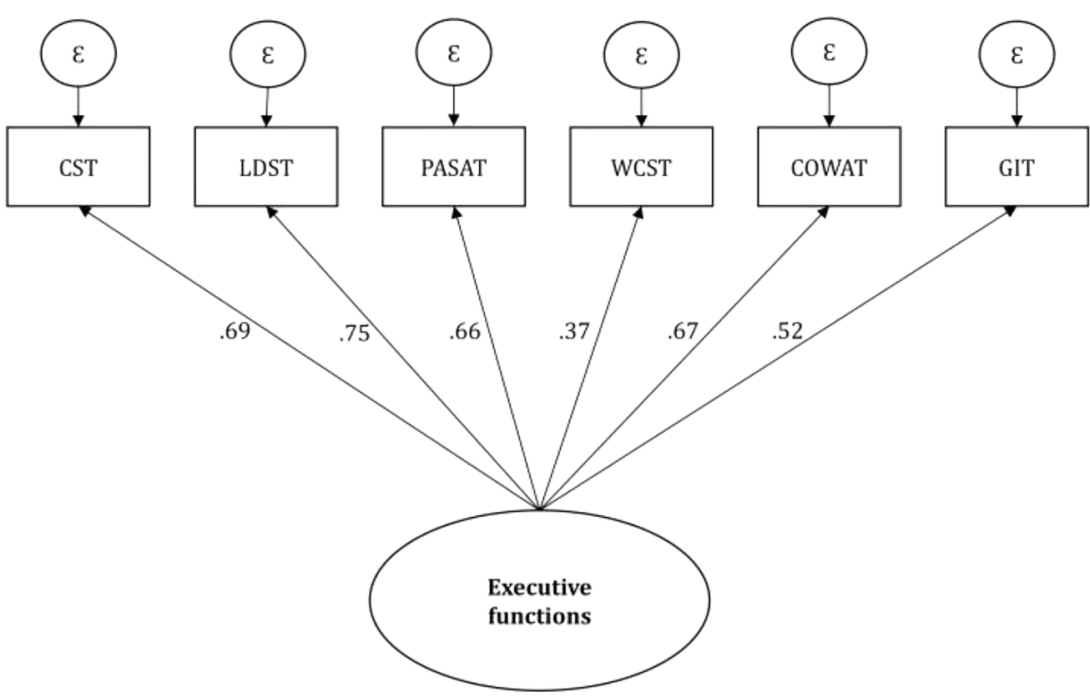

Fig. 1. Factor model for executive functions with standardized factor loadings. 
a)

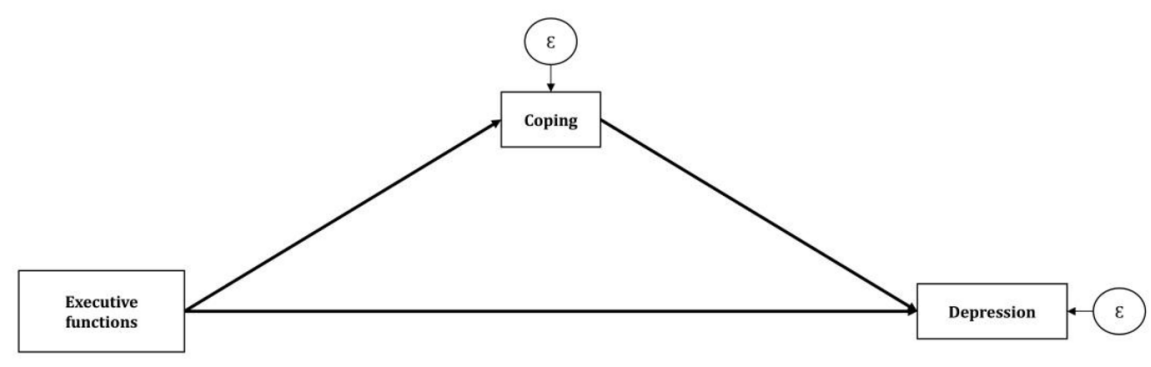

b)

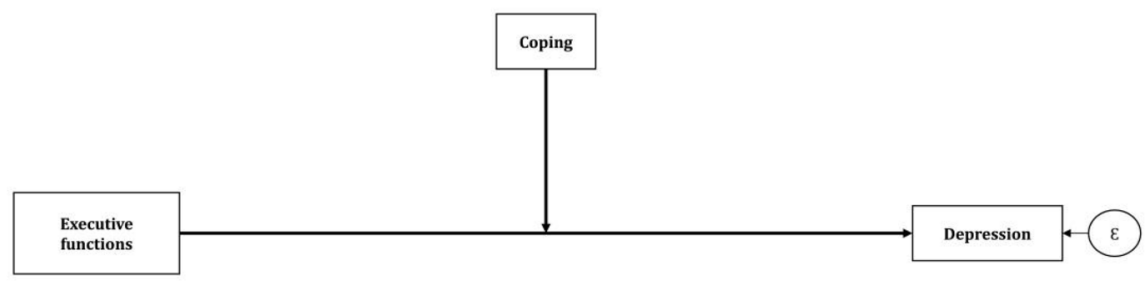

Fig. 2. Path models for mediation (a) and moderation (b) by coping of the association between executive functions and depression.

Table 1

Characteristics of the sample $(N=68$

\begin{tabular}{llll}
\hline & $\begin{array}{l}\text { Full sample } \\
(N=122)\end{array}$ & $\begin{array}{l}\text { Analysis sample } \\
(N=68)\end{array}$ & $P$-value \\
\hline Age in years, mean (SD) & $47.7(9.4)$ & $46.9(9.2)$ & .302 \\
Females, $n$ (\%) & $76(62.3)$ & $41(60.3)$ & .609 \\
Low education*, $n(\%)$ & $78(64.5)^{\mathrm{a}}$ & $42(62.7)^{\mathrm{a}}$ & .649 \\
Having a partner, $n(\%)$ & $102(83.6)$ & $53(77.4)$ & .058 \\
Employed, $n$ (\%) & $33(27.1)$ & $21(30.9)$ & .285 \\
MS type, $n(\%)$ & & $48(72.7)^{\mathrm{b}}$ & \\
$\quad$ Relapsing-remitting & $79(66.4)^{\mathrm{b}}$ & $19(15.2)^{\mathrm{b}}$ & .215 \\
$\quad$ Primary progressive & $20(16.8)^{\mathrm{b}}$ & $8(12.1)^{\mathrm{b}}$ & \\
$\quad$ Secondary progressive & $20(16.8)^{\mathrm{b}}$ & $6.7(7.8)^{\mathrm{d}}$ & $.387^{\mathrm{e}}$ \\
Time since diagnosis in years, & $7.1(8.1)^{\mathrm{c}}$ & & \\
$\quad$ mean (SD) & & $3.3(1.5)^{\mathrm{b}}$ & $.400^{\mathrm{e}}$ \\
Expanded Disability Status Scale & $3.4(1.6)^{\mathrm{b}}$ & & \\
$\quad($ EDSS), mean (SD) & & & \\
\hline
\end{tabular}

Note. Percentages might not add up to 100 due to rounding. Unless otherwise specified, $P$-values are from independent sample $t$-tests (for continuous variables) or $\chi$-tests (for categorical variables) comparing those in the analysis sample $(n=68)$ to those excluded $(n=54)$.

* The education levels are categorized according to the Dutch education system (Verhage, 1964). Low = senior secondary vocational education or lower. High = university of applied sciences or higher.

a Missing for 1 patient.

b Missing for 2 patients.

c Missing for 7 patients.

d Missing for 3 patients.

e Variable was not normally distributed and therefore a Mann-Whitney $U$ test was used.

between avoidance coping and the LDST and PASAT. As stated before, the EF factor was constructed by regression cognitive test sores on a continuous latent variable in the full sample $(N=122)$. CVLT delayed recall loaded very low on the $\mathrm{EF}$ factor (standardized factor loading $=-0.09$ ) and was therefore removed. For the remaining cognitive measures, factor loadings are shown in Fig. 1. Overall, the EF factor explained $81.2 \%$ of the covariance in the observed cognition variables.
Table 2

Clinical and cognitive outcomes $(N=68)$.

\begin{tabular}{|c|c|c|}
\hline & Mean (SD) & N (\%) impaired \\
\hline \multicolumn{3}{|l|}{ Coping CISS } \\
\hline Task-oriented coping & $57.2(11.3)$ & \\
\hline Emotion-oriented coping & $41.3(11.0)$ & \\
\hline Avoidance coping & $43.1(11.2)$ & \\
\hline Depressive symptoms HADS-D ( > 7) & $6.3(4.4)$ & $23(33.8)$ \\
\hline Fatigue Severity Scale (FSS) (> 3) & $5.5(1.0)$ & $66(97)$ \\
\hline Checklist Individual Strength (CIS-20-R) ( $>34$ ) & $41.3(10.8)$ & $51(75)$ \\
\hline \multicolumn{3}{|l|}{ Executive functions } \\
\hline CST shifting $z$-score ${ }^{\mathrm{a}}$ & $-0.4(1.2)$ & $13(19)$ \\
\hline LDST number correct $z$-score ${ }^{a}$ & $-0.8(1.1)$ & $22(33)$ \\
\hline PASAT $z$-score ${ }^{\mathrm{b}}$ & $-0.3(1.0)$ & $8(13)$ \\
\hline WCST perseveration error $t$-score ${ }^{c}$ & $48.3(8.3)$ & $4(6)$ \\
\hline COWAT education-corrected $t$-score ${ }^{\mathrm{a}}$ & $46.3(9.8)$ & $10(15)$ \\
\hline GIT animal fluency percentile ${ }^{\mathrm{a}}$ & $29.7(26.6)$ & $13(19)$ \\
\hline CVLT delayed memory recall $z$-score & $0.3(1.1)$ & $2(3)$ \\
\hline
\end{tabular}

CST $=$ Concept $\quad$ Shifting Test, LDST $=$ Letter-Digit $\quad$ Substitution Test, PASAT $=$ Paced Auditory Serial Addition Test, WCST $=$ Wisconsin Card Sorting Test, $\operatorname{COWAT}=$ Controlled Oral Word Association Test, GIT $=$ Groninger Intelligence Test, CVLT $=$ California Verbal Learning Test.

a Missing for 1 patient.

b Missing for 6 patients.

c Missing for 3 patients.

\subsection{Path analysis}

Next, a mediation model was tested in the analysis sample $(n=68)$ that included the three coping styles. Task-oriented coping $\left(b_{\text {direct }}=-0.03, \mathrm{SE}=0.01, p=.001\right)$ and emotion-oriented coping $\left(b_{\text {direct }}=0.03, \mathrm{SE}=0.01, p<.001\right.$ ) were significantly related to the depression outcome, but neither of them was associated with EF factor scores $\left(b_{\text {direct }}=2.43, \mathrm{SE}=5.62, p=.666\right.$ and $b_{\text {direct }}=-9.02$, $\mathrm{SE}=5.36, p=.092$, resp.). This was not unexpected since both coping styles had low correlations with individual EF tests (Table 3). Since a mediator has to be associated with both exposure (EF) and outcome (depression), this showed that EF is not a mediator of the effects of task- 
Table 3

Correlations among cognitive test performances and coping, depression and fatigue.

\begin{tabular}{lllllll}
\hline & $\begin{array}{l}\text { Task- } \\
\text { Oriented } \\
\text { Coping }\end{array}$ & $\begin{array}{l}\text { Emotion- } \\
\text { oriented } \\
\text { coping }\end{array}$ & $\begin{array}{l}\text { Avoidance } \\
\text { Coping }\end{array}$ & HADS-D $^{\mathrm{a}}$ & FSS $^{\mathrm{b}}$ & CIS-20-R $^{\mathrm{b}}$ \\
\hline CST $^{\mathrm{b}}$ & 0.03 & -0.21 & -0.22 & 0.04 & 0.03 & -0.07 \\
LDST & 0.08 & -0.17 & $-0.36^{* *}$ & -0.03 & 0.11 & -0.03 \\
PASAT & -0.02 & -0.08 & $-0.28^{*}$ & 0.12 & -0.01 & -0.14 \\
WCST & 0.03 & 0.01 & -0.08 & 0.01 & -0.08 & -0.24 \\
COWAT $^{\mathrm{b}}$ & 0.04 & -0.10 & -0.21 & 0.23 & -0.05 & -0.20 \\
GIT $^{\mathrm{b}}$ & 0.14 & -0.15 & 0.03 & -0.00 & 0.17 & 0.04 \\
CVLT & -0.18 & 0.15 & 0.21 & -0.05 & -0.09 & 0.12 \\
\hline
\end{tabular}

HADS-D = subscale depression of the Hospital Anxiety and Depression Scale, FSS $=$ Fatigue Severity Scale, CIS-20-R = Checklist Individual Strength-20, CST $=$ Concept $\quad$ Shifting Test,$\quad$ LDST $=$ Letter-Digit Substitution Test, PASAT $=$ Paced Auditory Serial Addition Test, WCST $=$ Wisconsin Card Sorting Test, COWAT ${ }^{\mathrm{a}}=$ Controlled Oral Word Association Test, $\mathrm{GIT}^{\mathrm{b}}=$ Groningen Intelligence Test, CVLT $=$ California Verbal Learning Test.

a A square-root transformation was used because variable was not normallydistributed.

b A logarithmic zero-skew transformation was used because variable was not normally-distributed.

$* p<.05$.

** $p<.01$.

oriented coping and emotion-oriented coping on depressive symptoms, so they were removed from the path model. The remaining model only retained the mediating effect of avoidance coping, as it showed signficiant associations with both exposure and outcome. This model showed that higher EF was negatively associated with avoidance coping $\left(b_{\text {direct }}=-14.44, \mathrm{SE}=5.31 p=.007\right)$, which in turn was negatively related to depressive symptoms $\left(\mathrm{b}_{\text {direct }}=-0.03, \mathrm{SE}=0.01, p=.001\right.$ ). In contrast, $\mathrm{EF}$ itself had a no significant direct effect on depressive symptoms ( $\mathrm{b}_{\text {direct }}=-0.13, \mathrm{SE}=0.44, p=.767$ ), but it had a positive indirect effect $\left(\mathrm{b}_{\text {indirect }}=0.44, \mathrm{SE}=0.21, p=.037\right)$. This indicates that better EF related to more depressive symptoms through less reliance on avoidance coping.

In the moderation models, no significant interactions were observed between $\mathrm{EF}$ and task-oriented coping $\left(\mathrm{b}_{\text {interaction }}=-0.04, \mathrm{SE}=0.04\right.$, $p=.316)$, emotion-oriented coping $\left(b_{\text {interaction }}=0.05, \mathrm{SE}=0.04\right.$, $p=.204$ ) or avoidance coping $\left(\mathrm{b}_{\text {interaction }}=0.02\right.$, $\mathrm{SE}=0.04$, $p=.726)$.

\section{Discussion}

The aim of the present study was to study the relationship between executive functioning, coping and depressive symptoms in MS patients. Measures of processing speed were associated with avoidance coping, while no other significant bivariate relations between measures of executive functioning, coping and depressive symptoms were found. Consistently, executive functioning factor scores were not related to task-oriented or emotion-oriented coping in the path analysis. Better executive functioning, however, was related to less reliance on avoidance coping, while less reliance on avoidance coping was related to more depressive symptoms. Testing of the mediating path showed that executive functioning was indeed significantly related to more depressive symptoms by less reliance on avoidance coping. There was no significant direct effect of executive functioning on depressive symptoms and no significant total effect, suggesting that the beneficial effect of better executive function on depressive symptoms was nullified by a relative underutilization of avoidance coping. Furthermore, there was no moderating effect of coping on the association between cognition and depressive symptoms. Taken together, findings suggest that executive functioning does not need to be taken into account when considering the relationship between task-oriented and emotion-oriented coping and depression in MS patients, but their mental health might benefit from more reliance on avoidance coping.

At first sight, avoidance coping may seem to be a maladaptive style of coping, but it has a rather different operationalization in the CISS, where it refers to actively seeking social support and distraction (De Ridder and Van Heck, 2004).

Our findings are in line with the evidence in patients with brain injury, for whom avoidance coping measured by the CISS has also been related to a better health status (Brands et al., 2014). Futhermore, our findings are in agreement with a previous study showing that seeking social support, categorized as avoidance coping, relates to better adjustment in MS patients (Dennison et al., 2009). In daily life, avoidance coping can be adaptive when problems are chronic and uncontrollable, as in conditions such as MS. If the patient realizes that symptoms are chronic and uncontrollable, the patient could decide not to let the problem influence him or her and instead to focus on something more interesting or valuable, like social support.

It is unclear why MS patients with better executive functions in our sample relied less on this coping strategy, and unfortunately we were unable to explore this in more depth. Notably, correlation analyses showed that they made equal use of other coping styles. While speculative, it might be that higher levels of awareness and social inhibition make them more reluctant to seek distraction or support from others.

Arnett et al. (2002) found a moderating effect of coping which seems in contrast to our findings. In their later longitudinal study they showed both moderating and mediating effects (Rabinowitz and Arnett, 2009). Results are difficult to compare because both studies used different instruments for executive functioning, coping and depression. Especially coping may differ because they used the Coping Orientation for Problem Experiences (COPE) instead of the CISS. It also has to be noticed that both studies are rather underpowered to allow the examination of interaction effects, and future large scale studies are needed to draw firm conclusions.

In our sample many patients showed reduced speed of information processing (33\%) measured with the LDST, which in turn was related to avoidance coping. Processing speed may be a critical variable in the associations between cognition, coping, and depression. Previously, it has been shown that processing speed may underly executive deficits (Leavitt et al., 2014). It can be debated whether the factor which we labelled EF is purely EF or a mix of EF and speed of information processing given the results of the factor loadings and the choice of tests. However, but we believe that this is something concerning EF in general, being an umbrella term for functions measured with different mainly speed-based - tests.

We are not aware of any other studies on the relationship between executive functioning, coping and depression in MS patients, but there are some studies in patients with brain injury which found mixed results as well. Our own study group did not find significant relationships between performance on executive functioning tests and coping and depression (Wolters Gregório et al., 2015), but self-reported executive functioning was related to passive coping, which is considered to be more maladaptive. Furthermore, coping influenced the relationship between executive functioning and QoL. Likewise, it would be interesting to measure self-reported executive functioning and the relationship between coping, executive functioning and QoL in patients with MS as well.

In the present study, there was no relationship between executive functioning and problem-oriented coping and emotion-oriented coping, as shown in other studies (Goretti et al., 2010; Krpan et al., 2007). Although we performed detailed measurements of both executive functioning and coping, our findings may be explained by the relatively low level of executive dysfunctioning in our sample. We also used retrospective data from medical files and only performed cross-sectional analyses. Furthermore, our sample consisted of many low-educated patients with mostly relapsing-remitting MS which may limit the generalizability of the results. 


\section{Conclusions}

Our findings suggest that executive functioning does not influence levels of depressive symptoms directly or indirectly via task-oriented and emotion-oriented coping styles in MS patients, but their mental health might benefit from more reliance on avoidance coping. These findings suggest that it seems of importance to stimulate a broad spectrum of coping strategies in MS, including avoidance coping styles, such as actively seeking support and distraction. Since the results of our studies and those of others, both in MS and brain injury, are still mixed, it is too early to formulate more specific recommendations for clinical practice. Coping, however, does seem to influence psychological outcome and should at least be taken into account during clinical assessment and when treatment plans are formulated. Because of the complex relationship between executive functioning, coping and psychosocial outcome in MS, further research is warranted.

\section{Declaration of Competing Interest}

None.

\section{Funding}

This research did not receive any specific grant from funding agencies in the public, commercial, or not-for-profit sectors.

\section{References}

Amato, M.P., Portaccio, E., Goretti, B., Zipoli, V., Ricchiuti, L., De Caro, M.F., ..., Trojano, M., 2006. The rao's brief repeatable battery and stroop test: normative values with age, education and gender corrections in an italian population. Mult. Scler. 12 (6), 787-793.

Amtmann, D., Bamer, A.M., Noonan, V., Lang, N., Kim, J., Cook, K.F., 2012. Comparison of the psychometric properties of two fatigue scales in multiple sclerosis. Rehabil. Psychol. 57 (2), 159-166.

Arnett, P.A., Smith, M.M., Barwick, F.H., Benedict, R.B., Ahlstrom, B.P., 2008. Oral motor slowing in multiple sclerosis: relationship to neuropsychological tasks requiring an oral response. J. Int. Neuropsychol. Soc. 14 (3), 454-462.

Arnett, P.A., Higginson, C.I., Voss, W.D., Randolph, J.J., Grandey, A.A., 2002. Relationship between coping, cognitive dysfunction and depression in multiple sclerosis. Clin. Neuropsychol. 16 (3), 341-355.

Benedict, R.B., 2005. Effects of using same- versus alternate-form memory tests during short-interval repeated assessments in multiple sclerosis. J. Int. Neuropsychol. Soc. 11 (6), 727-736.

Benedict, R.B., Wahlig, E., Bakshi, R., Fishman, I., Munschauer, F., Zivadinov, R., Weinstock-Guttman, B., 2005. Predicting quality of life in multiple sclerosis: accounting for physical disability, fatigue, cognition, mood disorder, personality, and behavior change. J. Neurol. Sci. 231 (1-2), 29-34.

Brands, I.H., Köhler, S., Stapert, S.Z., Wade, D.T., Van Heugten, C.M., 2014. Psychometric properties of the coping inventory for stressful situations (CISS) in patients with acquired brain injury. Psychol. Assess. 26 (3), 848-856.

Brands, I., Bol, Y., Stapert, S., Köhler, S., Van Heugten, C., 2018. Is the effect of coping styles disease specific? relationships with emotional distress and quality of life in acquired brain injury and multiple sclerosis. Clin. Rehabil. 32 (1), 116-126.

Chiaravalloti, N., .D.., DeLuca, J., 2008. Cognitive impairment in multiple sclerosis. Lancet Neurol. 7, 1139-1151.

Compston, A., Coles, A., 2008. Multiple sclerosis. Lancet 372 (9648), 1502-1517.

De Ridder, D.T.D., Van Heck, G.L., 2004. Coping Inventory for Stressful Situations: CISS Dutch Manual. Swets Test, Lisse, the Netherlands.

Dennison, L., Moss-Morris, R., Chalder, T., 2009. A review of psychological correlates of adjustment in patients with multiple sclerosis. Clin. Psychol. Rev. 29 (2), 141-153.

Fischer, J.S., Rudick, R.A., Cutter, G.R., Reingold, S.C., 1999. The multiple sclerosis functional composite measure (MSFC): an integrated approach to ms clinical outcome assessment. national ms society clinical outcomes assessment task force. Mult. Scl. 5 (4), 244-250.

Folkman, S., Lazarus, R.S., Gruen, R.J., DeLongis, A., 1986. Appraisal, coping, health status, and psychological symptoms. J Pers. Soc. Psychol. 50, 571-579.

Goretti, B., Portaccio, E., Zipoli, V., Hakiki, B., Siracusa, G., Sorbi, S., Amato, M.P., 2009. Coping strategies, psychological variables and their relationship with quality of life in multiple sclerosis. Neurol. Sci. 30 (1), 15-20.

Goretti, B., Portaccio, E., Zipoli, V., Hakiki, B., Siracusa, G., Sorbi, S., Amato, M.P., 2010. Impact of cognitive impairment on coping strategies in multiple sclerosis. Clin. Neurol. Neurosurg. 112 (2), 127-130.

Gregório, G.W., Brands, I., Stapert, S., Verhey, F.R., Van Heugten, C.M., 2014. Assessments of coping after acquired brain injury: a systematic review of instrument conceptualization, feasibility, and psychometric properties. J. Head Trauma Rehab. 29 (3), E30-E42.

Heaton, R.K., Chelune, G.J., Talley, J.L., Kay, G.G., Curtiss, G., 2003. Computerised Wisconsin Card Sort Task Version 4 (WCST). Psychological Assessment Resources, Odessa, FL.

Henry, J.D., Beatty, W.W., 2006. Verbal fluency deficits in multiple sclerosis. Neuropsychologia 44 (7), 1166-1174.

Hill, B.D., Alosco, M., Bauer, L., Tremont, G., 2012. The relation of executive functioning to cvlt-ii learning, memory, and process indexes. Appl. Neuropsychol. Adult 19 (3), 198-206.

Honarmand, K., Feinstein, A., 2009. Validation of the hospital anxiety and depression scale for use with multiple sclerosis patients. Mult. Scl. 15 (12), 1518-1524.

Koopman, F.S., Brehm, M.A., Heerkens, Y.F., Nollet, F., Beelen, A., 2014. Measuring fatigue in polio survivors: content comparison and reliability of the fatigue severity scale and the checklist individual strength. J. Rehabil. Med. 46 (8), 761-767.

Kristofferzon, M., Lindqvist, R., Nilsson, A., 2011. Relationships between coping, coping resources and quality of life in patients with chronic illness: a pilot study. Scand. J. Caring Sci. 25 (3), 476-483.

Krpan, K.M., Levine, B., Stuss, D.T., Dawson, D.R., 2007. Executive function and coping at one-year post traumatic brain injury. J. Clin. Exp. Neuropsychol. 29 (1), 36-46.

Krupp, L.B., LaRocca, N.G., Muir-Nash, J., Steinberg, A.D., 1989. The fatigue severity scale. application to patients with multiple sclerosis and systemic lupus erythematosus. Arch. Neurol. 46, 1121-1122.

Kurtzke, J.F., 1983. Rating neurologic impairment in multiple sclerosis: an expanded disability status scale (EDSS). Neurology 33 (11), 1444-1452.

Leavitt, V.M., Wylie, G., Krch, D., Chiaravalloti, N., DeLuca, J., Sumowski, J.F., 2014. Does slowed processing speed account for executive deficits in multiple sclerosis? evidence from neuropsychological performance and structural neuroimaging. Rehab. Psychol. 59 (4), 422-428.

Luteijn, F., Van der Ploeg, F.A.E., 1983. Groninger Intelligentie Test. Handleiding. [Groninger Intelligence Test. Manual.]. Swets \& Zeitlinger BV, Lisse, The Netherlands.

McDonald, W.I., Compston, A., Edan, G., Goodkin, D., Hartung, H.P., Lublin, F.D., ..., Wolinsky, J.S., 2001. Recommended diagnostic criteria for multiple sclerosis: guidelines from the international panel on the diagnosis of multiple sclerosis. Ann. Neurol. 50 (1), 121-127.

Mulder, J.L., Dekker, R., Dekker, P.H., 1996. Verbale Leer en Geheugen Test. Swets \& Zeitlinger, Lisse.

Parmenter, B.A., Zivadinov, R., Kerenyi, L., Gavett, R., Weinstock-Guttman, B., Dwyer, M.G., ..., Benedict, R.B., 2007. Validity of the wisconsin card sorting and delis-kaplan executive function system (DKEFS) sorting tests in multiple sclerosis. J. Clin. Exp. Neuropsychol. 29 (2), 215-223.

Rabinowitz, A.R., Arnett, P.A., 2009. A longitudinal analysis of cognitive dysfunction, coping, and depression in multiple sclerosis. Neuropsychology 23 (5), 581-591.

Rietberg, M.B., Van Wegen, E.H., Kwakkel, G., 2010. Measuring fatigue in patients with multiple sclerosis: reproducibility, responsiveness and concurrent validity of three dutch self-report questionnaires. Dis. Rehabil. 32 (22), 1870-1876.

Schmand, B., Groenink, S.C., Van den Dungen, M., 2008. Letter fluency: psychometric properties and dutch normative data. Tijdschr. Gerontol. Geriatr. 39 (2), 64-76.

Stegen, S., Stepanov, I., Cookfair, D., Schwartz, E., Hojnacki, D., Weinstock-Guttman, B., Benedict, R.H.B., 2010. Validity of the california verbal learning test-ii in multiple sclerosis. Clin. Neuropsychol. 24 (2), 189-202.

Van der Elst, W., Van Boxtel, M.J., Van Breukelen, G.P., Jolles, J., 2006a. The concept shifting test: adult normative data. Psychol. Assess. 18 (4), 424-432.

Van der Elst, W., Van Boxtel, M.J., Van Breukelen, G.P., Jolles, J., 2006b. The letter digit substitution test: normative data for 1,858 healthy participants aged 24-81 from the maastricht aging study (MAAS): influence of age, education, and sex. J. Clin. Exp. Neuropsychol. 28 (6), 998-1009.

Vercoulen, J.H.M.M., Alberts, M., Bleijenberg, G., 1999. De checklist individual strength (CIS). Gedragstherapie 32, 131-136.

Verhage, F., 1964. Intelligentie En leeftijd: Onderzoek bij Nederlanders van Twaalf Tot Zevenenzeventig Jaar. Van Gorcum, Assen.

Wolters, G., Stapert, S., Brands, I., Van Heugten, C., 2011. Coping following acquired brain injury: predictors and correlates. J. Head Trauma Rehabil. 26 (2), 150-157.

Wolters Gregório, G.M., Ponds, R.W., Smeets, S.M., Jonker, F., Pouwels, C.G., Verhey, F.R., Van Heugten, C.M., 2015. Associations between executive functioning, coping, and psychosocial functioning after acquired brain injury. Br. J. Clin. Psychol. 54 (3), 291-306.

Zigmond, A.S., Snaith, R.P., 1983. The hospital anxiety and depression scale. Acta Psychiatr. Scand. 67 (6), 361-370. 